\title{
Secondary lesions to curatives in central venous catheters: an observational intervention study
}

\author{
Janaína da Silva Flôr, Taiana Saraiva, Clarice Birnfeld, Juliana Moraes, Cláudia Rocha, Keron Sanches, \\ Marina Moraes, Valesca Cezar
}

\section{Introduction}

Treatments performed for patients in hematologic therapy centres require central venous access for chemotherapy infusion, volêmicas and electrolyte repositions, nutritional support, blood components, and others. With this, patients are exposed to the adverse effects of therapies in which they are subjected and to the prolonged use of central catheters, presenting as a consequence: cutaneous fragility and skin lesions arising from the use of antiseptic solutions and Different types of coverings for bandages.

\section{Methodology}

It is a study of observational case, in patients of a hematologic unit of a hospital in southern Brazil that presented secondary skin lesions to the agents used in the maintenance of the central venous access curatives, from October 2016 to February 2017, describing the adequacy of aseptic technique adopted in the exchange of curative in patients with skin lesions in the vicinity of the venous device.

\section{Results}

Five patients were observed, for which the technique of exchange of the central venous catheter dressing was modified, performing: Sepsis of the insertion of the catheter and its adjacencies with chlorhexidine $0.5 \%$ and in the sequence performed the removal of this agent with serum Physiological $0.9 \%$, remaining antiseptic solution only in insertion. After that, cover was applied with sterile transparent film. This procedure demonstrated the decrease of hyperemia in the area adjacent to the insertion of the catheter with better healing of areas with abrasive lesions.

\section{Conclusion}

Patients mentioned decreased burning symptoms, providing greater comfort, lowering pathways of infection and maintaining the adequacy of the correct techniques and safety in patient care. It is up to the nurse responsible for patient care to be aware of the agents causing these effects and the preservation of cutaneous integrity, minimizing the risk of infections arising from these lesions. 